Research Article

\title{
Simulation Research on Trapped Oil Pressure of Involute Internal Gear Pump
}

\author{
Shanxin Guo $\mathbb{D}^{1}$ and Xiangfeng Guan $\mathbb{1}^{2}$ \\ ${ }^{1}$ College of Electronics and Information Science, Fujian Jiangxia University, Fuzhou 350108, China \\ ${ }^{2}$ Smart Home Information Collection and Processing on Internet of Things Laboratory of Digital Fujian, Fuzhou 350108, China \\ Correspondence should be addressed to Xiangfeng Guan; xfguan@fjjxu.edu.cn
}

Received 27 September 2020; Revised 27 December 2020; Accepted 7 January 2021; Published 18 January 2021

Academic Editor: A. M. Bastos Pereira

Copyright (C) 2021 Shanxin Guo and Xiangfeng Guan. This is an open access article distributed under the Creative Commons Attribution License, which permits unrestricted use, distribution, and reproduction in any medium, provided the original work is properly cited.

\begin{abstract}
The main structure of an internal gear pump consisted of an internal gear pair, including an internal gear and an external gear. The internal gear pump had oil trapping phenomenon like other hydraulic gear pumps. In order to solve the oil trapping phenomenon of involute gear pump with internal meshing tooth profile, in this paper, the mathematical equation of gear outer contour is established according to the principle of generation method, and the variation law of the trapped oil area in meshing process is deduced by theoretical instantaneous flow rate obtained by scanning method. Then, the minimum trapped oil volume and unloading area are solved by the graphic method. Finally, based on fluid mechanics and dynamics, the trapped oil pressure model is obtained. The change of the trapped oil area and trapped oil pressure in a meshing cycle is simulated by MATLAB. The results show that the trapped oil area changes in a parabola, and the trapped pressure fluctuates in mountains and valleys. When the trapped area is the smallest, the trapped oil pressure reaches the peak at the corresponding corner. The research results can provide guidance for the development of high-performance internal gear pumps.
\end{abstract}

\section{Introduction}

In order to ensure the continuous and uniform oil supply of the gear pump, two pairs of gear teeth engaging in meshing are needed in the internal gear pump for a certain period of time. It results in a closed dead volume which is not connected with the inlet and outlet cavities [1]. The size of the closed dead volume changes periodically with the rotation of the gear, resulting in a dramatic change of the working pressure [2]. This phenomenon is usually called the oil trapping phenomenon of a gear pump, which is the main source of gear pump noise and cavitation [3]. It can cause hazards such as pressure swing, pressure shock, and flow pulsation in the hydraulic system [4]. Therefore, it is of great significance to avoid the so-called oil trapping phenomenon of the gear pump. However, because the trapped oil area is surrounded by complex curves such as the outer contour of gear, involute, or cycloid [5], it is very difficult to obtain the continuous and uniform oil supply. Up to date, there is much research on the oil trapping phenomenon of the external gear pump and cycloid gear [6], and great improvements have been made. In comparison with external gear pump and cycloid gear, internal gear pumps have advantages such as lighter weight, smaller volume, and higher pressure due to their geometric structure [7]. Because the internal gear has oil ports in the diameter direction and the oil trapping process is different from other gear pumps, the high-pressure internal gears are not easy to obtain by conventional fabrication methods of internal gears. The common internal meshing gears are arc tooth profile, conjugate tooth profile, involute tooth profile, and so forth. Most research is focused on arc tooth profile and conjugate tooth profile and there are a few studies on involute tooth profile [8]. In this study, in order to solve the oil trapping phenomenon of gear pump with involute tooth profile during the process of internal meshing, the contour of internal gear is obtained by means of an imaginary rack cutter generating internal gear, and the model of trapped oil 
volume is established. Then, the design parameters and the change of trapped oil volume in the process of gear rotation are described, and then the trapped oil pressure is simulated. The research conclusion can provide an effective reference for the design and manufacture of the high-performance internal gear pump.

\section{Mathematical Model}

2.1. Oil Trapped Model of Internal Gear Pump. Gear pairs are commonly manufactured by the generative method [9]. Figure 1(a) shows the processing of external gears by the rack tool generating method, and Figure 1(b) shows the processing of the internal gears by the virtual rack tool generating method. The outer contour of the rack cutter is composed of line segments $A B, C D, D E$, and arc $B C$. The parameters of $h_{a}, c_{n}, h_{f}$, and $r_{0}$ are the addendum height, head clearance coefficient, total tooth height, and tool fillet, respectively. The parameters $\alpha, x$, and $p$ are pressure angle, the profile shift coefficient, and pitch, respectively. A rectangular coordinate system $s_{t}\left(O_{t} x_{t} y_{t}\right)$ is established at the center of the rack tool, and the mathematical equation of the rack tool is described as [10]

$$
R_{t}^{c}\left(x_{t}\right)=\left[\begin{array}{llll}
R_{t}^{A B} & R_{t}^{B C} & R_{t}^{C D} & R_{t}^{D E}
\end{array}\right]=\left[\begin{array}{c}
x_{t}^{c} \\
y_{t}^{c} \\
1
\end{array}\right] .
$$

The coordinate systems of gears $O_{s}$ and $O_{s^{\prime}}$ are $s_{s}\left(O_{s} x_{s} y_{s}\right)$ and $s_{s^{\prime}}\left(O_{s^{\prime}} x_{s^{\prime}} y_{s^{\prime}}\right)$, respectively. Their origins coincide with the gear axis and rotate with the gear axis. At the same time, the coordinate system $s_{e}\left(O_{e} x_{e} y_{e}\right)$ fixedly connected with the earth is established. During the forming process, the rack tool translates in the $x_{t}$ direction, and the displacement is $s$. At this moment, the gear $O_{s}$ rotates around $O_{e}$ and the rotation angle is $\varphi_{s}$, which satisfies the following motion relationship:

$$
s=r_{s} \varphi_{s} .
$$

In the above equation, $r_{s}$ is the gear pitch radius [11]:

$$
r_{s}=0.5 \mathrm{mz} \text {, }
$$

where $m$ and $z$ are the modulus of the gear and the number of teeth, respectively.

According to the generation principle, the relationship between the tooth profile of the gear and the tooth profile of the rack tool can be expressed by the following equation [12]:

$$
R_{s}^{p}\left(\varphi_{s}, x_{t}\right)=M_{s t}\left(\varphi_{s}\right) R_{t}^{c}\left(x_{t}\right),
$$

where the vector $R_{s}^{p}\left(\varphi_{s}, x_{t}\right)$ is the envelope of the tooth profile surface family of the rack tool and the matrix $M_{s t}\left(\varphi_{s}\right)$ is the transformation matrix from the coordinate system $s_{s}$ to the coordinate system $s_{t}$.

In the same way, the internal gear contour equation is obtained by the method of generating internal gears by imaginary rack tools:

$$
R_{t}^{p}\left(\varphi_{s^{\prime}}, x_{t}\right)=M_{s^{\prime} t}\left(\varphi_{s^{\prime}}\right) R_{t}^{c}\left(x_{t}\right) .
$$

In the formula, the vector $R_{t}^{p}\left(\varphi_{s^{\prime}}, x_{t}\right)$ is the envelope of the rack tool tooth profile surface family, and the matrix $M_{s^{\prime} t}\left(\varphi_{s^{\prime}}\right)$ is the transformation matrix from the coordinate system $s_{s^{\prime}}$ to the coordinate system $s_{t}$.

2.2. Calculation of Trapped Oil Volume. The principle of the internal gear pump trapping oil is shown in Figure 2. The theoretical instantaneous flow $Q_{s h}$ of the internal gear pump can be expressed as [13], which is derived [14] as

$$
Q_{s h}=B \omega\left(r_{a}^{2}-r^{2}-r_{j}^{2} \varphi^{2}\right) .
$$

In equation (6), $B$ is the gear face width, $\omega$ is the angular velocity of the gear pump; $r_{a}$ is the addendum circle radius; $r$ is the gear reference radius; $r_{j}$ is the gear base circle radius, and $\varphi$ is the driving gear rotation angle.

The scanning volume $V_{s h}$ changes with the change of the driving gear rotation angle $\varphi$ and the rate of change is [15]

$$
\frac{\mathrm{d} V_{s h}}{\mathrm{~d} \varphi}=\frac{Q_{s h}}{\omega}=B\left(r_{a}^{2}-r^{2}-r_{j}^{2} \varphi^{2}\right) .
$$

Figure 3 shows the relationship between the meshing point and the angle of rotation. The rotation angles corresponding to $F, G, G^{\prime}$, and $F^{\prime}$ are $\varphi_{F}, \varphi_{G}, \varphi_{G^{\prime}}$, and $\varphi_{F^{\prime}}$, respectively. The length between $G$ and $G^{\prime}$ is $h_{j}$. The relationship between the rotation angles is $\varphi_{G}=(\pi / z)-\varphi_{F}$, $\varphi_{G^{\prime}}=\left(1+\left(2 h_{j} / t_{j}\right)\right)(\pi / z)-\varphi_{F}$, and $\varphi_{F^{\prime}}=(2 \pi / z)-\varphi_{F}$. The parameter of $t_{j}$ is the base pitch.

The corresponding scan volume change rate is described as follows:

$$
\begin{aligned}
& \frac{\mathrm{d} V_{F}}{\mathrm{~d} \varphi_{F}}=B\left(r_{a}^{2}-r^{2}-r_{j}^{2} \varphi_{F}^{2}\right), \\
& \frac{\mathrm{d} V_{G}}{\mathrm{~d} \varphi_{G}}=B\left(r_{a}^{2}-r^{2}-r_{j}^{2} \varphi_{G}^{2}\right), \\
& \frac{\mathrm{d} V_{G^{\prime}}}{\mathrm{d} \varphi_{G^{\prime}}}=B\left(r_{a}^{2}-r^{2}-r_{j}^{2} \varphi_{G^{\prime}}^{2}\right), \\
& \frac{\mathrm{d} V_{F^{\prime}}}{\mathrm{d} \varphi_{F^{\prime}}}=B\left(r_{a}^{2}-r^{2}-r_{j}^{2} \varphi_{F^{\prime}}^{2}\right),
\end{aligned}
$$

The change of trapped oil volume $V, V_{1}$, and $V_{2}$ with driving gear rotation angle $\varphi$ is obtained by equations (8)-(11):

$$
\begin{aligned}
\frac{\mathrm{d} V}{\mathrm{~d} \varphi} & =\frac{4 \pi}{z} B r_{j}^{2}\left(\varphi-\frac{\pi}{z}\right), \\
\frac{\mathrm{d} V_{1}}{\mathrm{~d} \varphi} & =\frac{2 \pi}{z}\left(1-\frac{2 h_{j}}{t_{j}}\right) B r_{j}^{2}\left[\varphi-\frac{\pi}{2 z}\left(1-\frac{2 h_{j}}{t_{j}}\right)\right], \\
\frac{\mathrm{d} V_{2}}{\mathrm{~d} \varphi} & =\frac{2 \pi}{z} B r_{j}^{2}\left(\varphi-\frac{3 \pi}{2 z}\right) .
\end{aligned}
$$

Integrating equations (12)-(14), 


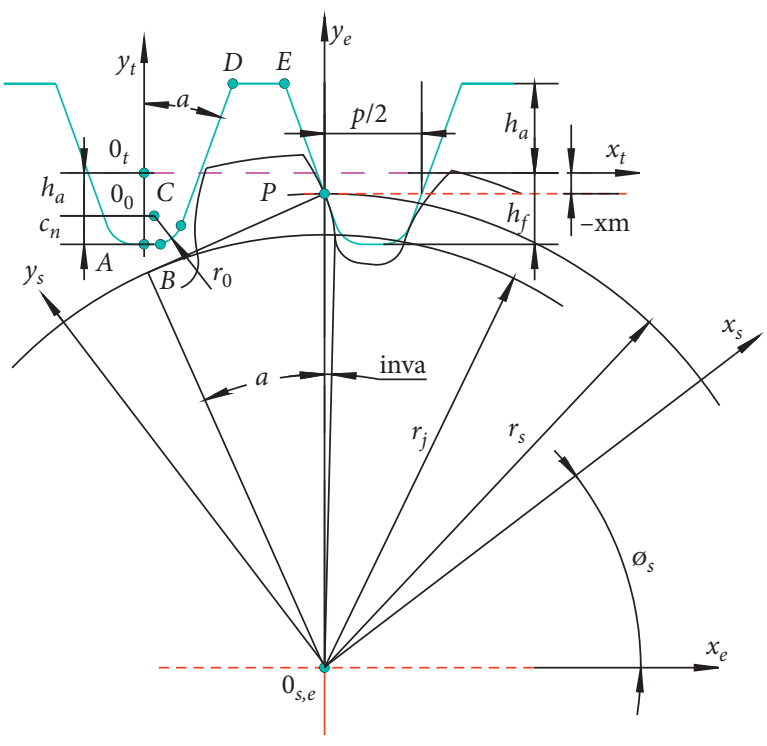

(a)

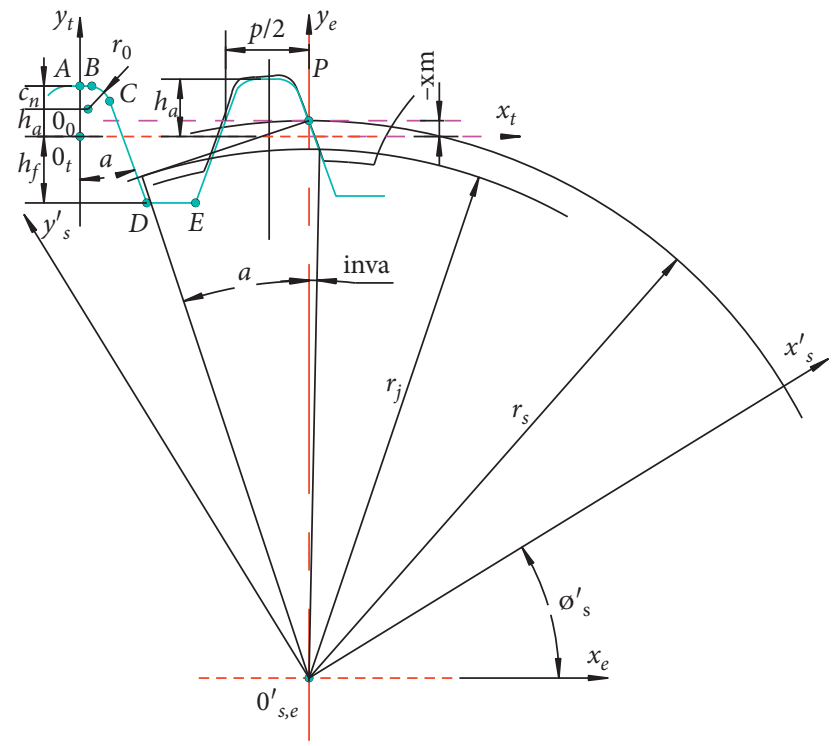

(b)

Figure 1: (a) Process external gears by generating method. (b) Virtual rack tool, internal gear processing by the generative method.
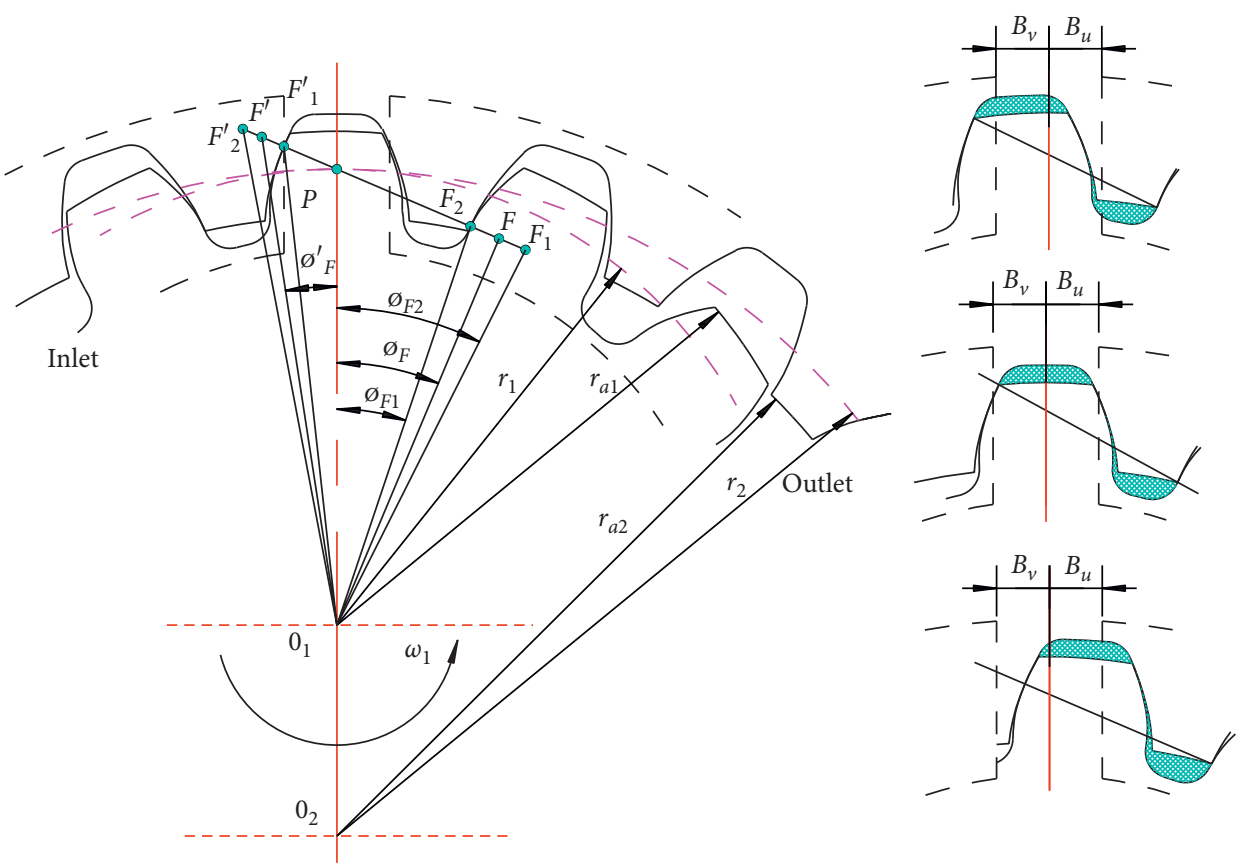

FIgURE 2: Oil trapping principle of the internal gear pump.

$V=V_{0}+\frac{2 \pi}{z} B r_{j}^{2}\left(\varphi-\frac{\pi}{z}\right)^{2}$

$V_{1}=V_{10}+\frac{\pi}{z}\left(1-\frac{2 h_{j}}{t_{j}}\right) B r_{j}^{2}\left[\varphi-\frac{\pi}{2 z}\left(1-\frac{2 h_{j}}{t_{j}}\right)\right]^{2}$,

$V_{2}=V_{20}+\frac{\pi}{z} B r_{j}^{2}\left(\varphi-\frac{3 \pi}{2 z}\right)^{2}$
From equations (15)-(17), $V, V_{1}$, and $V_{2}$ are the quadratic functions of the rotation angle $\varphi$. When $\varphi=(\pi / z)$, $(\pi / 2 z)\left(1-\left(2 h_{j} / t_{j}\right)\right),(3 \pi / z)$, the minimum values $V_{0}, V_{10}$, and $V_{20}$ are obtained, respectively.

2.3. Graphical Method to Solve the Minimum Trapped Oil Volumes $\mathbf{V}_{0}, \mathbf{V}_{10}, \mathbf{V}_{20}$. According to the definition of the trapped oil [5] and Figure 3, let $V_{\widehat{o 1 F^{\prime} F}}, V_{\widehat{o 2 F^{\prime} F}}, V_{o 1 G^{\prime} F 3}$, and 


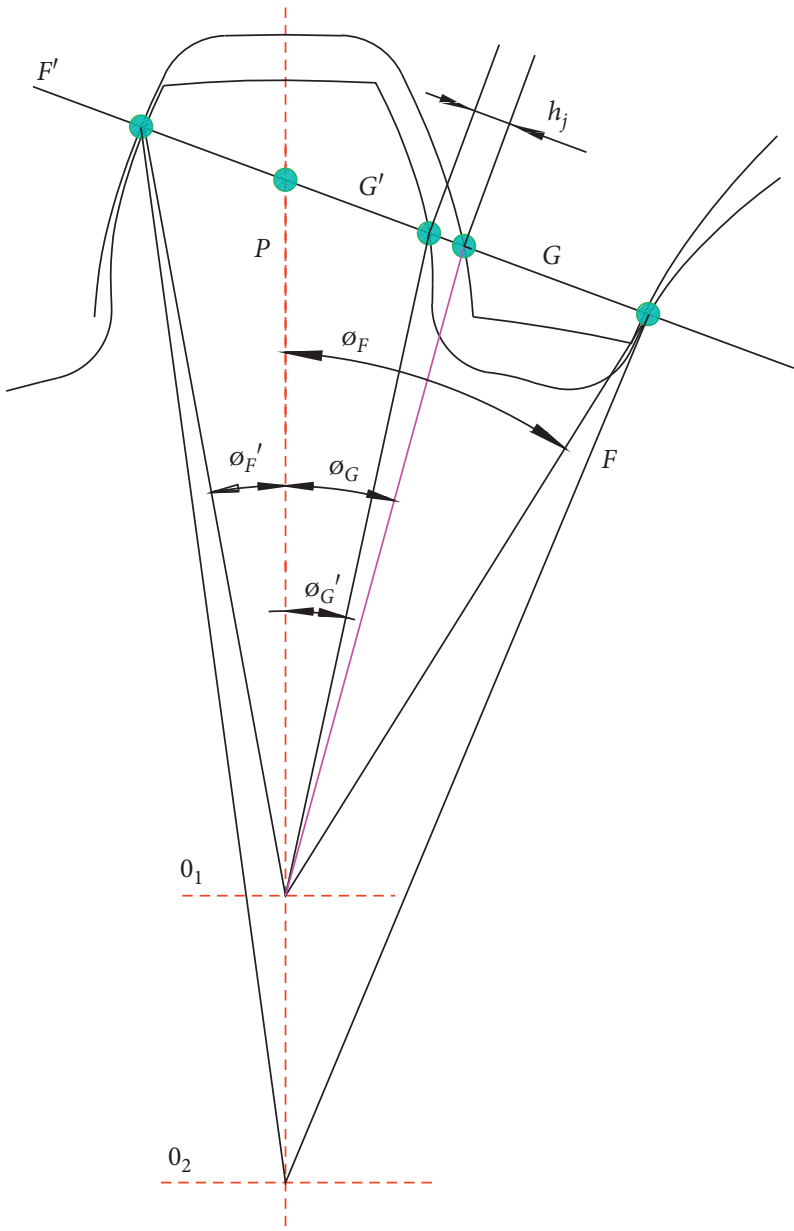

Figure 3: The relationship between the meshing point and the angle of rotation.

$V_{\widehat{O 2 G F 3}}$ be the center of circle $O_{1}, O_{2}$ sector area, respectively. Let $V_{\triangle o 102 F}$ and $V_{\triangle o 102 F^{\prime}}$ be the triangle area enclosed by $O_{1}$,
$\mathrm{O}_{2}, F, F^{\prime}, G$, and $G^{\prime}$, respectively. Then, the trapped oil volume can be described as

$$
\begin{aligned}
& V=V \widehat{o 2 F^{\prime} F}-V \widehat{o 1 F^{\prime} F}-\left(V_{\Delta o 102 F}+V_{\Delta o 102 F^{\prime}}\right)=V_{\widehat{o 2 F^{\prime} F}}-V_{\widehat{o 1 F^{\prime} F}}-0.5 e t_{j} \cos \alpha^{\prime}, \\
& V_{1}=V_{\triangle o 1 G^{\prime} F 3}-V_{\widehat{o 1 G^{\prime} F 3}}+\left(V_{\triangle 02 G F 3}-V_{\widehat{o 2 G F 3}}\right), \\
& V_{2}=V-V_{1} .
\end{aligned}
$$

In the equation, $e$ and $\alpha^{\prime}$ are the distance between the center of the gear and the meshing angle of the gear pair.

In Figures 4 and 5, as the driving gear angle $\varphi$ changes, $V \widehat{O 2 F^{\prime} F}$ and $V \widehat{O 1 F^{\prime} F}$ are composed of two parts: the unchanged area $V_{A}$ and the changing area $V_{B}$. Then, the trapped oil volume $V$ can also be expressed as

$$
V=V_{A}+V_{B}-0.5 e t_{j} \cos \alpha^{\prime} .
$$

In the equation, $V_{A}$ consists of four sectors of area. The radius of the sector are the addendum circle $r_{a, 1}, r_{a, 2}$ and the tooth root circle $r_{f, 1}, r_{f, 2}$. The corresponding included angles of the sector are $\beta_{11}, \beta_{21}$ enclosed:

$$
V_{A}=0.5 r_{a, 2}^{2} \beta_{21}+0.5 r_{f, 2}^{2} \beta_{22}-0.5 r_{a, 1}^{2} \beta_{12}-0.5 r_{f, 1}^{2} \beta_{11}
$$

The derivation of area $V_{B}$ is shown in Figure 6. The volume $V_{B \theta}$ occupied by the spread angle $\theta$ can be obtained by the following equation [16]:

$$
V_{B \theta}=0.5 B \int r_{k}^{2} \mathrm{~d} \theta+C .
$$

In the equation, the pressure angle corresponding to the $r_{k}$ radius on the tooth profile is $\theta$.

Solve equation (21) definite integral: 


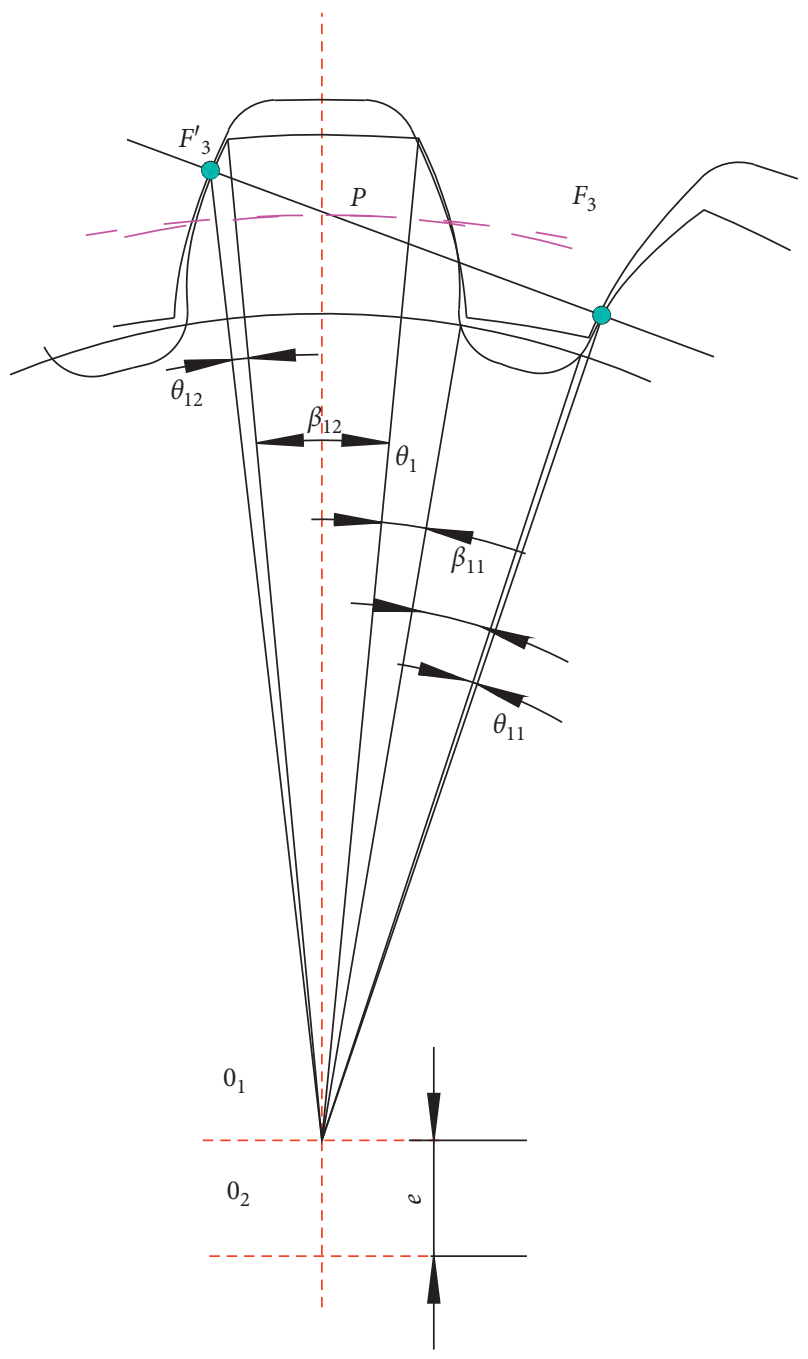

FIGURE 4: The relationship between the trapped oil and the rotation angle of the external gear.

$$
V_{\theta}=\frac{B r_{j}^{3}}{6} r_{a}^{3} .
$$

According to the principle of involute [17],

$$
r=\theta+\alpha=\tan \alpha \text {. }
$$

Therefore, when $r=r_{a}$, equation (22) can be written as

$$
V_{\theta}=\frac{B r_{j}^{3}}{6} \tan ^{3} r_{a}
$$

It can be derived from this that

$$
\begin{aligned}
V_{B}= & \frac{B r_{j}^{3}}{6}\left(\tan ^{3} \theta_{21}+\tan ^{3} \theta_{22}+\tan ^{3} \theta_{2}-\tan ^{3} \theta_{11}-\tan ^{3} \theta_{12}\right. \\
& \left.-\tan ^{3} \theta_{1}\right) .
\end{aligned}
$$

$\theta_{1}, \theta_{11}, \theta_{12}, \theta_{2}, \theta_{21}$, and $\theta_{22}$ are the spread angles corresponding to the meshing points.

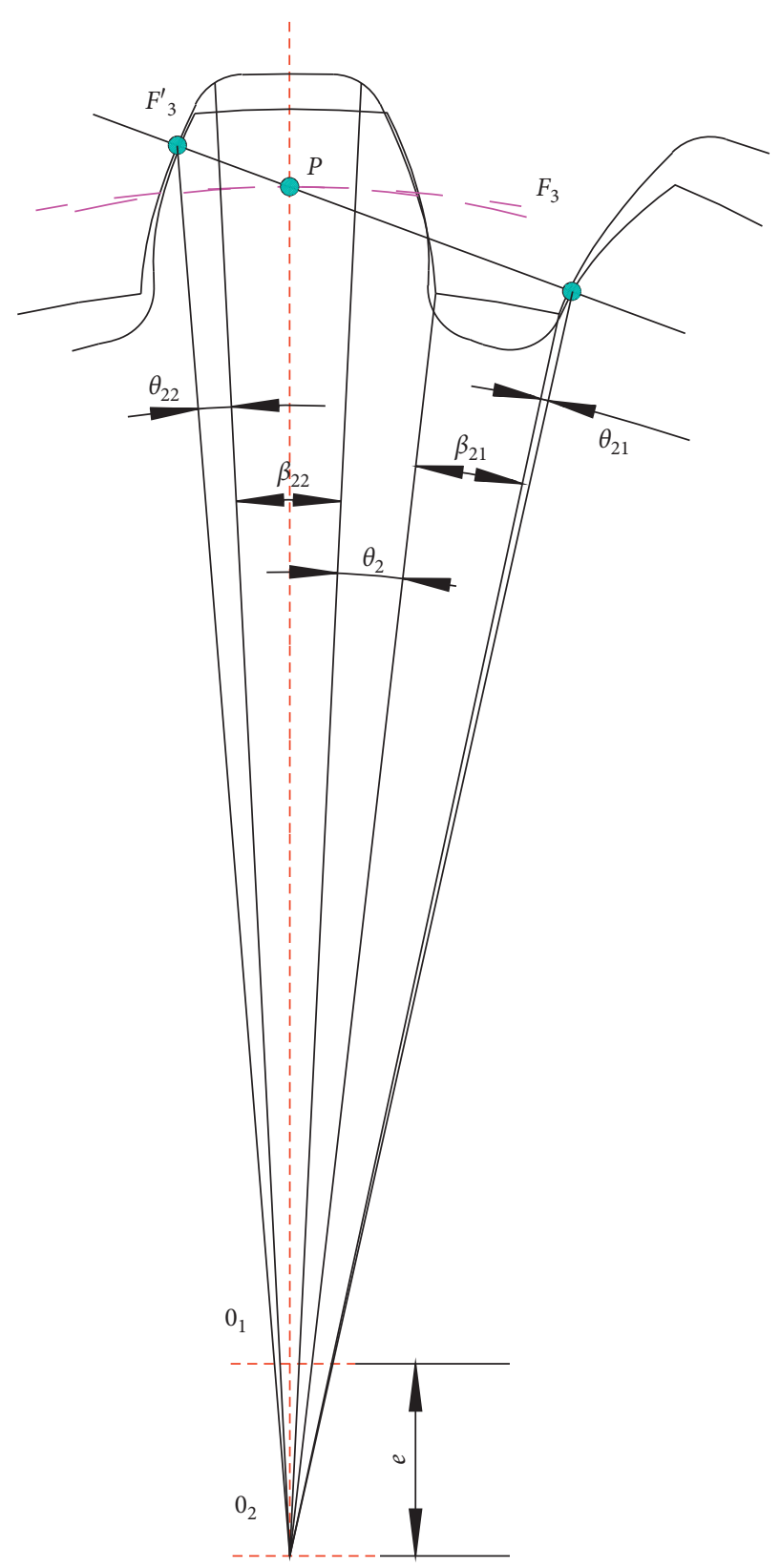

FIGURE 5: The relationship between the trapped oil and the rotation angle of the internal gear.

According to equations (15) and (19), (20), and (25), $V_{0}$ can be obtained.

From equation (16) and (17), the positions of $V_{10}$ and $V_{20}$ are shown in Figures 7 and 8, respectively. $V_{10}$ and $V_{20}$ can be obtained from (19), (20), (24), and (25).

2.4. Unloading Area. As shown in Figure 9, points $P, F$ are node and meshing points, respectively. Let the length of $P, F$ be $f$, and the relationship between $f$ and the gear rotation angle $\varphi$ is [18]

$$
f(\varphi)=0.5 t_{j}-r_{j}\left(\varphi-\frac{\pi}{z}\right) .
$$




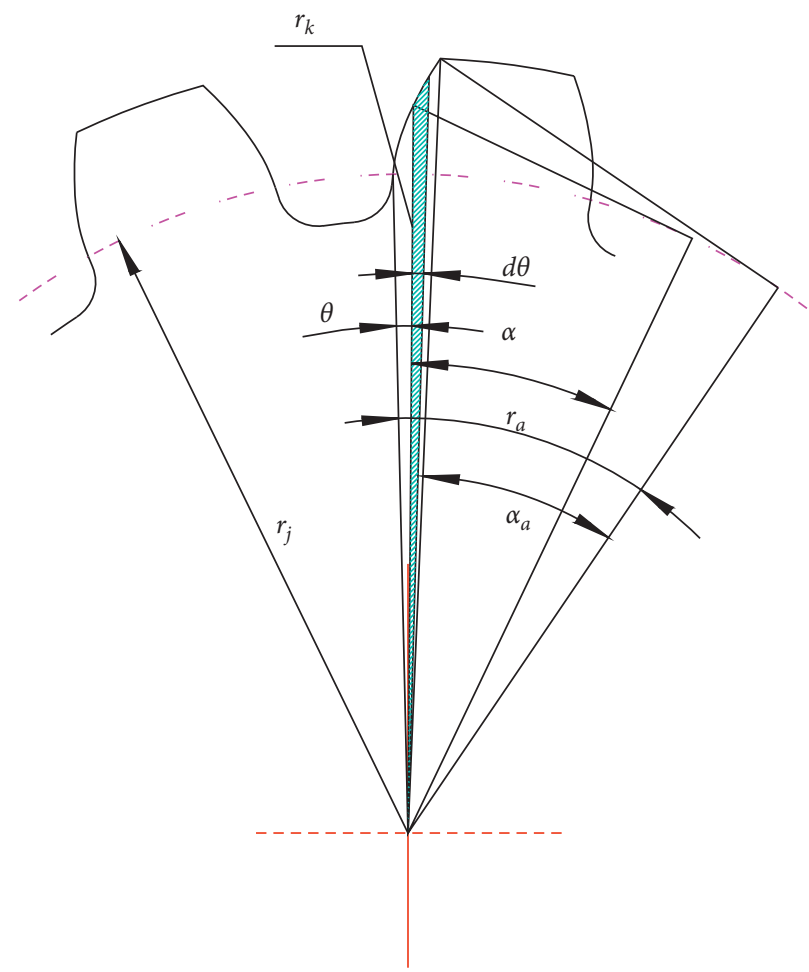

FIgURE 6: The relationship between area and expansion angle.

The unloading area is the area where the cross section of the trapped oil volume is located in the unloading groove [19]. In Figure 9, the calculation steps of $S_{u 1 v 1}$ and $S_{u 2 v 2}$ are as follows: (1) Calculate the expression of $f(\varphi)$ at points $F, 1,2$, $3,4,5,6$ on the gear tooth profile. (2) Find the curve equations of $12,23,34,4 F, F 5,56$. (3) Solve the integral to calculate the unloading area, the method, and steps referring to $[20]$.

In the calculation process of $S_{u 2 v 2}, f(\varphi)$ can be replaced with $\left[t_{j}-f(\varphi)\right]$, and the other steps can be calculated according to $S_{u 1 v 1}$.

$V_{\mathrm{a}}, V_{b}$ are the actual trapped oil volume:

$$
\begin{aligned}
& V_{a}=V_{1}-S_{u 1 v 1}, \\
& V_{b}=V_{2}-S_{u 2 v 2 .}
\end{aligned}
$$

\section{Oil Trapped Pressure Model of Internal \\ Gear Pump}

Figure 10 shows the trapped oil pressure model of the internal gear pump. Let the pressures of $V_{1}, V_{2}$, inlet chamber, and outlet chamber be $P_{1}, P_{2}, P_{\text {in }}$, and $P_{\text {out }}$, respectively. Let $q_{1}, q_{2}$, and $q_{h}$ be the unloading flow rate from the trapped oil cavity $V_{1}$ to the oil outlet cavity, the unloading flow rate from the trapped oil cavity $V_{2}$ to the oil inlet cavity, and the unloading flow rate from the trapped oil cavity $V_{2}$ to trapped oil cavity $V_{1}$, respectively. According to fluid mechanics and dynamics, the following is derived:

$$
\begin{aligned}
& \left\{\begin{array}{l}
q_{1}=C V_{a} \sqrt{\frac{2}{\rho}} \sqrt{\left|P_{1}-P_{\text {out }}\right|} \operatorname{sign}\left(P_{1}-P_{\text {out }}\right), \\
q_{2}=C V_{b} \sqrt{\frac{2}{\rho} \sqrt{\left|P_{2}-P_{\text {in }}\right|}} \operatorname{sign}\left(P_{2}-P_{\text {in }}\right), \\
q_{h}=C V_{h} \sqrt{\frac{2}{\rho} \sqrt{\left|P_{1}-P_{2}\right|}} \operatorname{sign}\left(P_{1}-P_{2}\right), \\
q_{2}-q_{h}=-\frac{\mathrm{d} V_{b}}{\mathrm{~d} t}-\frac{V_{b}}{\beta} \frac{\mathrm{d} P_{2}}{\mathrm{~d} t}, \\
q_{1}+q_{h}=-\frac{\mathrm{d} V_{a}}{\mathrm{~d} t}-\frac{V_{a}}{\beta} \frac{\mathrm{d} P_{1}}{\mathrm{~d} t}, \\
\frac{\mathrm{d} P_{1}}{\mathrm{~d} t}=-\frac{\beta}{V_{a}}\left[\left(q_{1}+q_{h}\right)+\frac{\mathrm{d} V_{a}}{\mathrm{~d} t}\right], \\
\frac{\mathrm{d} P_{2}}{\mathrm{~d} t}=-\frac{\beta}{V_{b}}\left[\left(q_{2}-q_{h}\right)+\frac{\mathrm{d} V_{b}}{\mathrm{~d} t}\right] .
\end{array}\right.
\end{aligned}
$$

In above equations, $\rho, \beta$ are the density and bulk elastic modulus of the fluid, respectively. $C$ is the flow coefficient 0.60-0.65. $V_{h}=h_{j} \times B$.

According to $\mathrm{d} \varphi=\omega \mathrm{d} t$, 


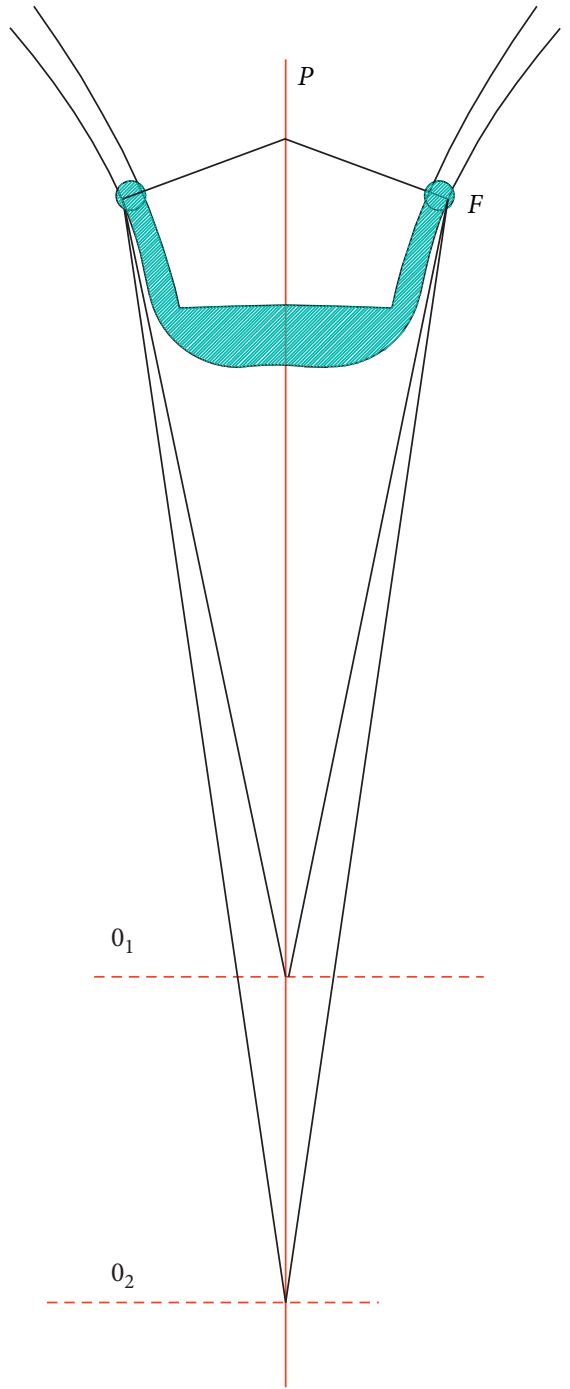

Figure 7: The Minimum value of $V_{10}$.

$$
\left\{\begin{array}{l}
\frac{\mathrm{d} P_{1}}{\mathrm{~d} \varphi}=-\frac{\beta}{\omega V_{a}}\left[\left(q_{1}+q_{h}\right)+\omega \frac{\mathrm{d} V_{a}}{\mathrm{~d} \varphi}\right] \\
\frac{\mathrm{d} P_{2}}{\mathrm{~d} \varphi}=-\frac{\beta}{\omega V_{b}}\left[\left(q_{2}-q_{h}\right)+\omega \frac{\mathrm{d} V_{b}}{\mathrm{~d} \varphi}\right] .
\end{array}\right.
$$

Let, $k_{1}=(\beta / \omega) C \sqrt{2 / \rho}, k_{2}=(2 \pi / z) B r_{j}^{2}, k_{3}=(2 \pi / z)(1-$ $\left.\left(2 h_{j} / t_{j}\right)\right) B r_{j}^{2}, k_{4}=(\pi / 2 z)\left(1-\left(2 h_{j} / t_{j}\right)\right), k_{5}=(3 \pi / 2 z), k_{6}$ $=\beta k_{2}, k_{7}=\beta k_{3}, k_{8}=V_{h} k_{1}$. Then,

$$
\left\{\begin{array}{l}
\frac{\mathrm{d} P_{1}}{\mathrm{~d} \varphi}=-k_{1} \sqrt{P_{1}-P_{\text {out }}}-\frac{k_{8} \sqrt{P_{1}-P_{2}}}{V_{10}+0.5 k_{3}\left[\varphi-k_{4}\right]^{2}}-\frac{k_{7}\left[\varphi-k_{4}\right]}{V_{10}+0.5 k_{3}\left[\varphi-k_{4}\right]^{2}}, \\
\frac{\mathrm{d} P_{2}}{\mathrm{~d} \varphi}=-k_{1} \sqrt{P_{2}-P_{\text {in }}}+\frac{k_{8}}{V_{20}+0.5 k_{2}\left(\varphi-k_{5}\right)^{2}} \sqrt{P_{1}-P_{2}}-\frac{k_{6}\left(\varphi-k_{5}\right)}{V_{20}+0.5 k_{2}\left(\varphi-k_{5}\right)^{2}} .
\end{array}\right.
$$




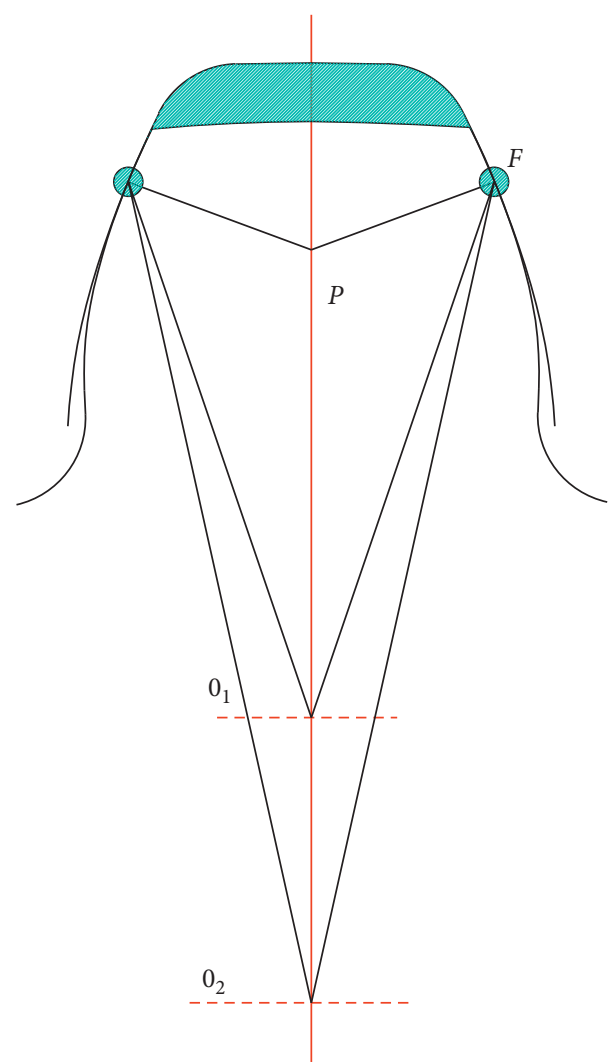

Figure 8: The Minimum value of $V_{20}$.

\section{Simulation Research}

4.1. Gear Parameters and Simulation. Input parameters, modulus $m=3$, pressure angle $\alpha=20^{\circ}$, tooth number $z_{1} / z_{2}=13 / 19$, addendum height coefficient $h_{a 1} / h_{a 2}=1 / 1$, radial clearance coefficient $c_{n 1} / c_{n 2}=0.25 / 0.25$, total tooth height $h_{f 1} / h_{f 2}=6.734 / 6.766$, tool fillet $r_{0}=0.25$, the profile shift coefficient $x_{1} / x_{2}=0.432 / 0.504$, and base pitch $t_{j}=8.856$. According to MATLAB simulation by equations (4) and (5), a pair of gears processed by the generative method is shown in Figure 11.

4.2. Simulation Results. When the inlet pressure $p_{i}=0 \mathrm{MPa}$ and the outlet pressure $p_{o}=10 \mathrm{MPa}$, the rotation process of the gear pair is simulated. During this process, the change trend of the trapped oil volumes $V_{1}$, $V_{2}, V$ is shown in Figure 12. It can be seen that the change of $V_{1}, V_{2}$ is parabolic. When the rotation angle is $0.12 \mathrm{rad}$, the minimum value is $2.34 \mathrm{~mm}^{3}$, and when the rotation angle is $0.36 \mathrm{rad}$, the minimum value is $2.12 \mathrm{~mm}^{3} . V$ is the sum of $V_{1}$ and $V_{2}$, and its changing trend is to first reach a low point and then present an increasing trend. Internal gear pumps and external gear pumps have similar changes $[21,22]$. During a period of gear tooth meshing, simulate the pressure changes in $V_{1}$ and $V_{2}$. There is no backlash between the front gear and the rear gear. When $h_{j}=0$, the changes of $p_{1}$ and $p_{2}$ are shown in Figure 13. $p_{1}$ and $p_{2}$ have a large variation range, and there are positive pressure and negative pressure in the interval. When the

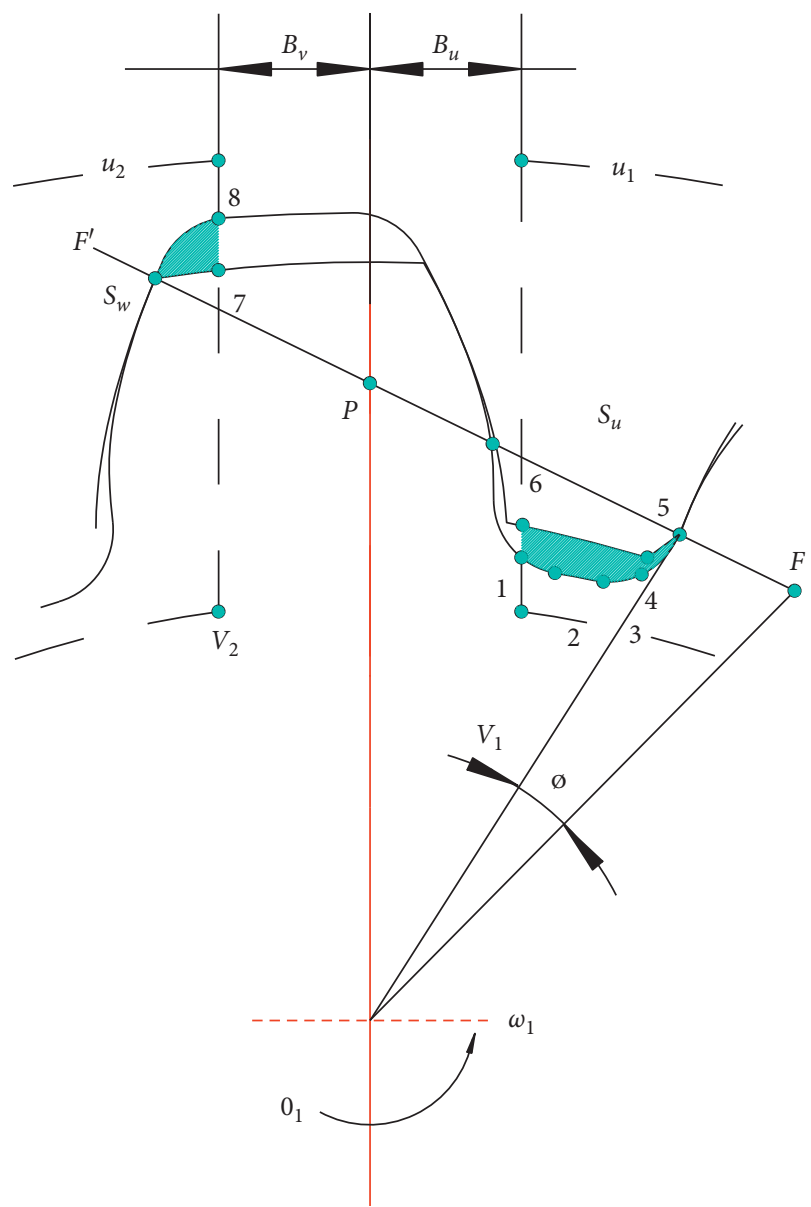

Figure 9: Calculation of the unloading area.

gear rotation angle reaches $0.12 \mathrm{rad}, p_{1}$ reaches the peak value of $35.5 \mathrm{MPa}$. When the corner reaches $0.36 \mathrm{rad}, p_{2}$ reaches the peak value of $40.2 \mathrm{MPa}$. If there is a backlash between the front gear and the rear gear, when $h_{j}=0.06 \mathrm{~m}$, the changes of $p_{1}$ and $p_{2}$ are shown in Figure 14 . It can be seen that the pressure change trend in the trapped oil zone is similar to that in Figure 13, but the change range is convergent. When the turning angle reaches $0.12 \mathrm{rad}, p_{1}$ reaches the peak value of $30.2 \mathrm{MPa}$. When the rotation angle reaches $0.36 \mathrm{rad}, p_{2}$ reaches the peak value of $20.24 \mathrm{MPa}$. If there is tooth side clearance $h_{j}=0.06 \mathrm{~m}$, and a rectangular unloading groove is designed in the oil trapped area, the position of the boundary line of the unloading groove is $B_{v}=B_{u}=0.5 \pi \mathrm{m}$, and the pressure change trend in the oil trapped area is shown in Figure 15. The change trends of $p_{1}$ and $p_{2}$ are very similar to those in Figures 13 and 14, and the range of change is more convergent. When the rotation angle reaches $0.12 \mathrm{rad}, p_{1}$ reaches the peak value of $16.5 \mathrm{MPa}$, and when the rotation angle reaches $0.36 \mathrm{rad}, p_{2}$ reaches the peak value of $18.2 \mathrm{MPa}$. Internal gear pumps have lower trapped oil pressure than external gear pumps [23] and arc gear pumps [24]. The design of tooth side clearance and unloading groove can slow down trapped oil pressure and reduce peak pressure. 


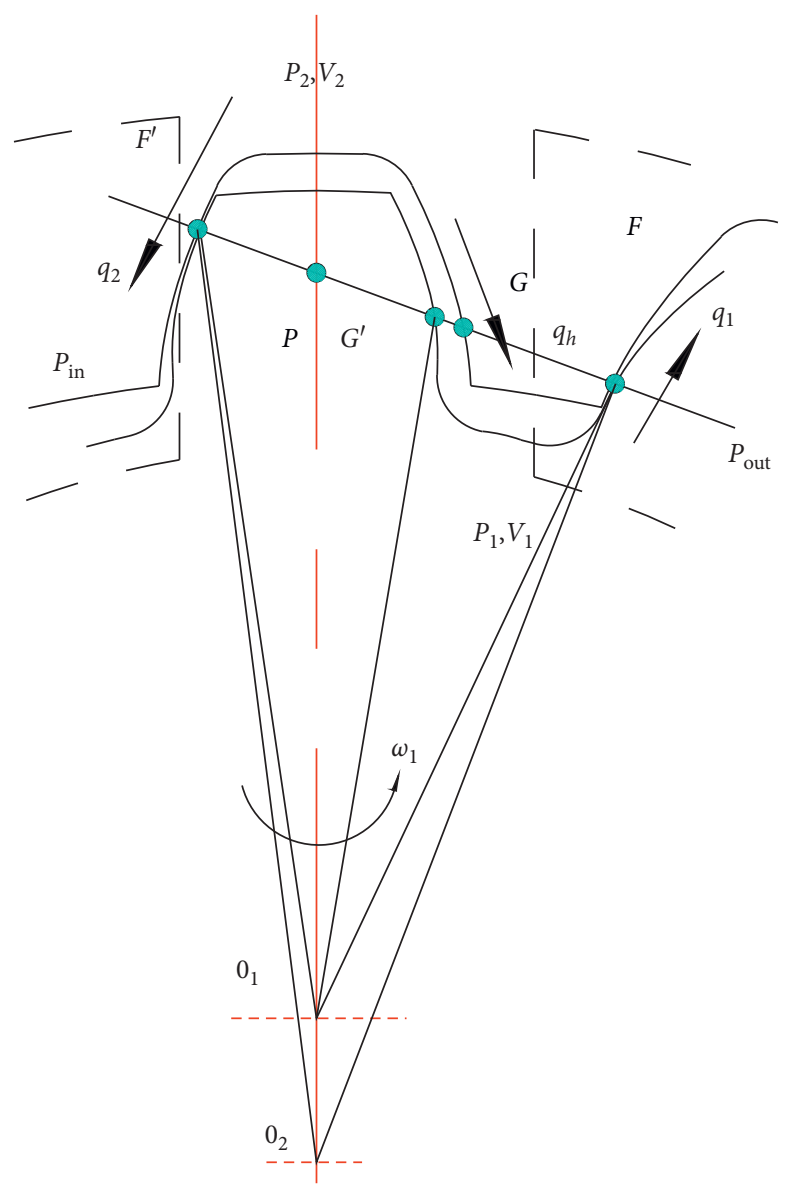

FIGURE 10: Trapped oil pressure model of the internal gear pump.

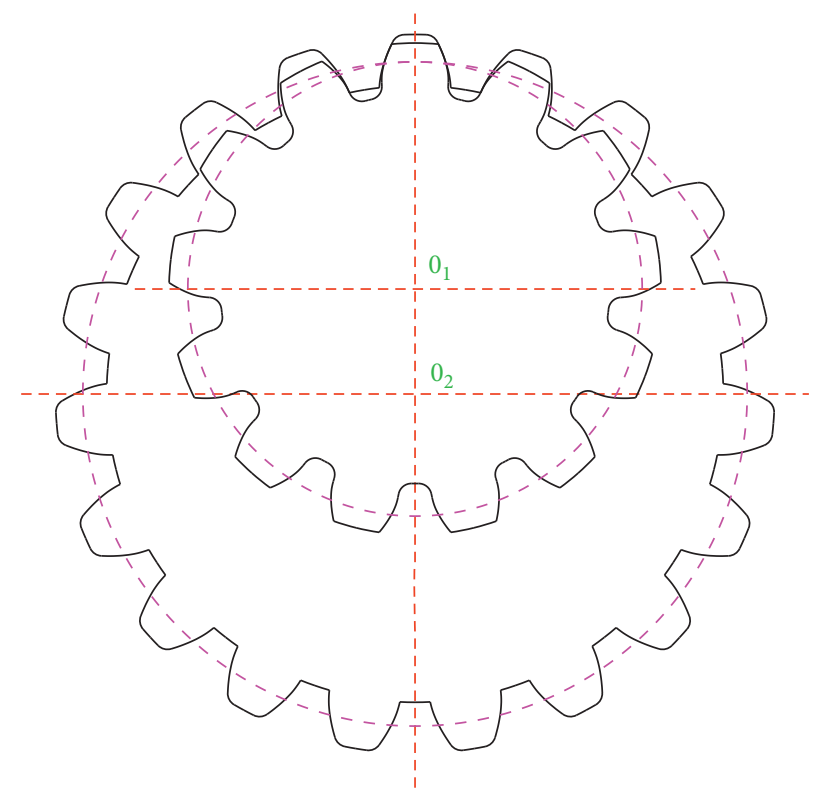

FIGURE 11: A pair of gears processed by the generative method. 


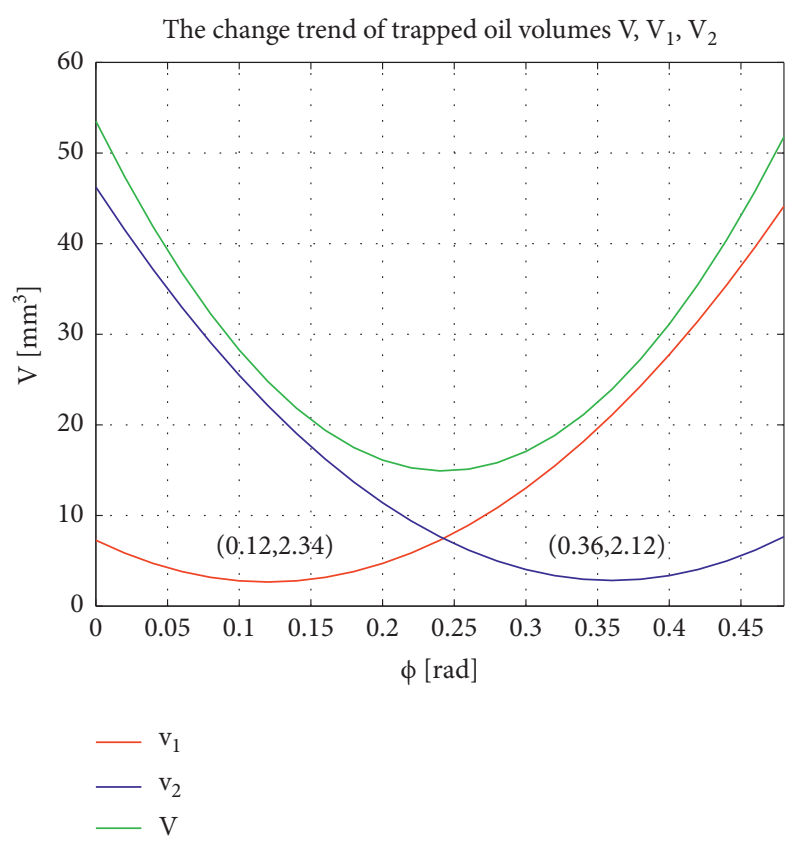

Figure 12: Changes in trapped oil volume.

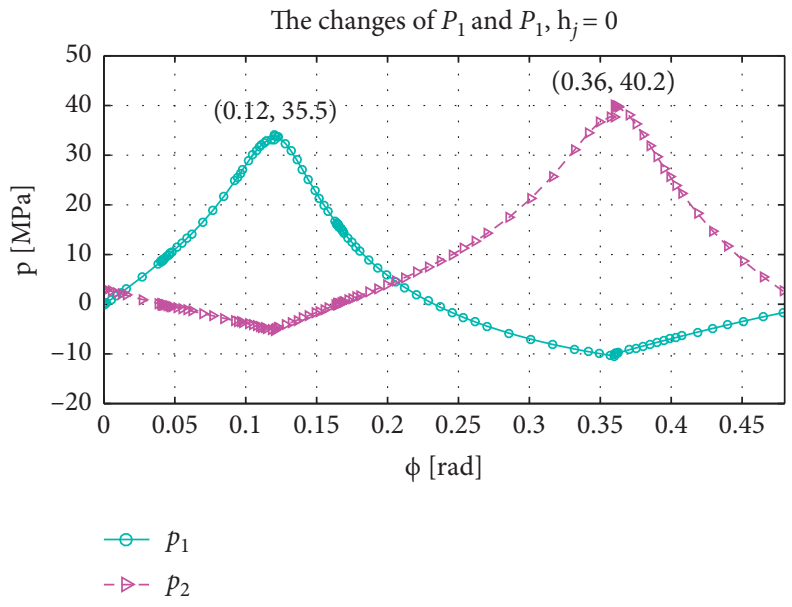

FIGURE 13: $h_{j}=0$, changes in trapped oil pressure.

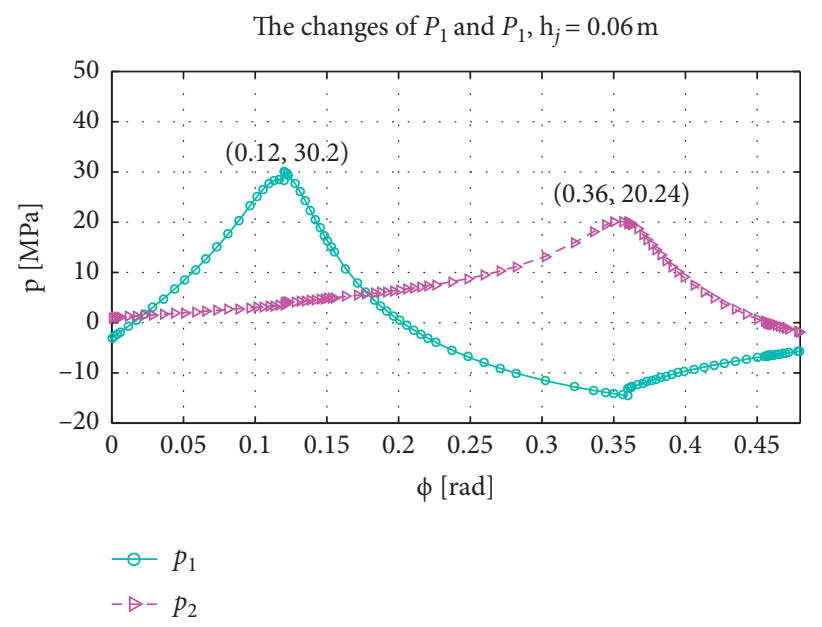

Figure 14: $h_{j}=0.06 \mathrm{~m}$, changes in trapped oil pressure. 


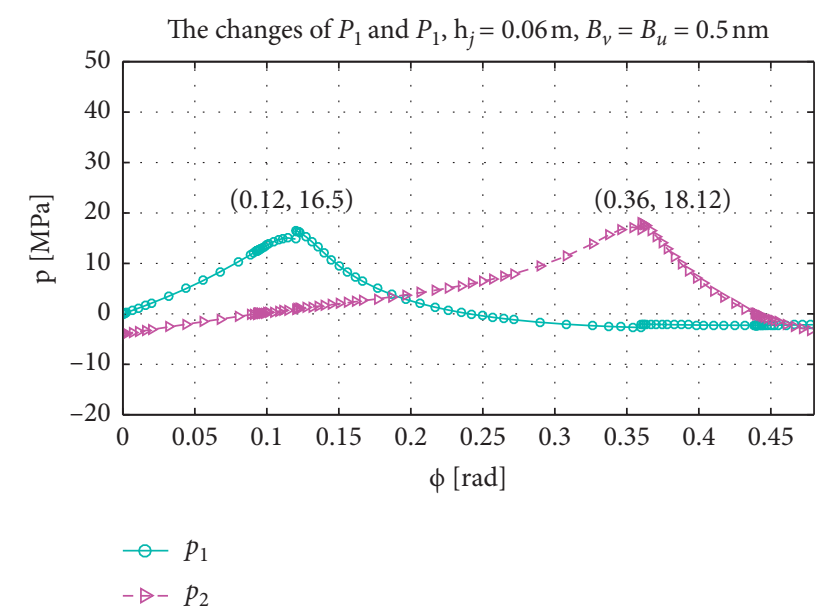

Figure 15: $h_{j}=0.06 \mathrm{~m}, B_{v}=B_{u}=0.5 \pi m$, changes in trapped oil pressure.

\section{Conclusions}

(1) For a pair of internal gear pairs processed by the generative method, there are oil trapped areas between the gear teeth during meshing, and the trapped oil volumes $V_{1}$ and $V_{2}$ present a parabolic change law, and each has a minimum value, which changes periodically when the gear rotates.

(2) When the internal gear pump rotates, the trapped oil pressures $p_{1}$ and $p_{2}$ increase first and then decrease with the change of the rotation angle. There is a maximum peak value. When the volume of the trapped oil cavity is the smallest, the trapped oil pressure reaches the maximum.

(3) The tooth side clearance will improve the oil trapping characteristics of the internal gear pump and reduce the pressure peak in the trapped oil cavity.

(4) The design of the unloading groove will improve the fluidity of trapped oil, reduce the range of trapped oil pressure, and reduce the pressure peak in the trapped oil cavity.

\section{Nomenclature}

$\begin{array}{ll}\text { AB: } & \text { The outer contour of the rack cutter } \\ \text { BC: } & \text { The outer contour of the rack cutter } \\ \text { CD: } & \text { The outer contour of the rack cutter } \\ \text { DE: } & \text { The outer contour of the rack cutter } \\ h_{\mathrm{a}}: & \text { Addendum height } \\ h_{\mathrm{a} 1}: & \text { Addendum height } \\ h_{\mathrm{a} 2}: & \text { Addendum height } \\ c_{\mathrm{n}}: & \text { Head clearance coefficient } \\ h_{\mathrm{f}}: & \text { Total tooth height } \\ h_{\mathrm{f} 1}: & \text { Total tooth height } \\ h_{\mathrm{f} 2}: & \text { Tool fillet height } \\ r_{0}: & \text { Pressure angle } \\ \alpha: & \text { The profile shift coefficient } \\ x: & \text { The profile shift coefficient } \\ x_{1}: & \end{array}$

$x_{2}$

$p:$

$s_{t}\left(O_{t} x_{t} y_{t}\right): \quad$ A rectangular coordinate system

$\mathrm{O}_{s}$ :

$\mathrm{O}_{s^{\prime}}$ :

$s_{s}\left(O_{s} x_{s} y_{s}\right): \quad$ A rectangular coordinate system of gear $O_{s}$

$s_{s^{\prime}}\left(O_{s^{\prime}} x_{s^{\prime}} y_{s^{\prime}}\right)$ : A rectangular coordinate system of gear $O_{s^{\prime}}$

$s_{e}\left(O_{e} x_{e} y_{e}\right): \quad$ A rectangular coordinate system

$x_{t}$ :

$s:$

$\mathrm{O}_{e}$ :

$\varphi_{s}$ :

$r_{s}:$

$m:$

$z$ :

$z_{1}$ :

$z_{2}$ :

$R_{s}^{p}\left(\varphi_{s}, x_{t}\right)$ :

$M_{s t}\left(\varphi_{s}\right):$

$s_{s}:$

$s_{t}$ :

$R_{t}^{p}\left(\varphi_{s^{\prime}}, x_{t}\right)$ :

$M_{s^{\prime} t}\left(\varphi_{s^{\prime}}\right):$

$s_{s^{\prime}}$ :

$Q_{\text {sh }}$ :

$B$ :

$\omega:$

$r_{a}:$

$r:$

$r_{j}$ :

$\varphi:$

$V_{s h}$ :

$\varphi_{F}$ :

$\varphi_{G}:$

$\varphi_{G^{\prime}}:$

$\varphi_{F^{\prime}}$ :

$h_{j}:$

$t_{j}:$

$V_{1}$ :

$V_{2}$ :

$V_{0}$ :

$V_{10}$ :

$V_{20}$ :

$V$ -

$V^{o 1 F^{\prime} F}$ :

$V^{O 2 F^{\prime} F}:$

$V_{\triangle o 102 F}^{o 1 G^{\prime} F}$ :

$V_{\triangle o 102 F^{\prime}}$ :

e:

$\alpha^{\prime}$ :

$V_{A}$ :

$V_{B}$ :

$r_{a, 1}$ :

$r_{a, 2}$ :

$\beta_{12}$ :

The profile shift coefficient

Pitch

Center of gear $\mathrm{O}_{s}$

Center of gear $\mathrm{O}_{s}$

Displacement direction

Displacement

Origin of $s_{e}$

The rotation angle

The gear pitch radius

The modulus of the gear

The number of teeth

The number of teeth

The number of teeth

The envelope of the tooth profile surface family of the rack tool

The transformation matrix

The coordinate system

The coordinate system

The envelope of the rack tool tooth profile surface family

The transformation matrix

The coordinate system

The theoretical instantaneous flow

The gear face width

The angular velocity of the gear pump

The addendum circle radius

The gear reference radius

The gear base circle radius

The driving gear rotation angle

The scanning volume

The rotation angle of $F$

The rotation angle of $G$

The rotation angle of $G^{\prime}$

The rotation angle of $F^{\prime}$

The length between $G$ and $G^{\prime}$

The base pitch

Trapped oil volume

Trapped oil volume

Trapped oil volume

The minimum values of $V$

The minimum values of $V_{1}$

The minimum values of $V_{2}$

$O_{1}, F, F^{\prime}$, sector area

$\mathrm{O}_{2}, F, F^{\prime}$, sector area

$\mathrm{O}_{2}, G^{\prime}, \mathrm{F}_{3}$, sector area

$\mathrm{O}_{1}, \mathrm{O}_{2}, \mathrm{~F}$, triangle area

$\mathrm{O}_{1}, \mathrm{O}_{2}, \mathrm{~F}^{\prime}$, triangle area

The distance between the centers of the gear

The meshing angle of the gear pair

The unchanged area

The changing area

The addendum circle

The addendum circle

Addendum angle 


\begin{tabular}{|c|c|}
\hline$\beta_{21}:$ & Addendum angle \\
\hline$r_{f, 2}:$ & The tooth root circle \\
\hline$r_{f, 1}:$ & The tooth root circle \\
\hline$\beta_{11}:$ & Tooth root circle included angle \\
\hline$\beta_{21}:$ & Tooth root circle included angle \\
\hline$\theta:$ & The spread angle \\
\hline$r_{k}:$ & The radius on the tooth profile \\
\hline$\theta_{1}:$ & $\begin{array}{l}\text { The spread angles corresponding to the } \\
\text { meshing points }\end{array}$ \\
\hline$\theta_{11}$ & $\begin{array}{l}\text { The spread angles corresponding to the } \\
\text { meshing points }\end{array}$ \\
\hline$\theta_{12}$ & $\begin{array}{l}\text { The spread angles corresponding to the } \\
\text { meshing points }\end{array}$ \\
\hline$\theta_{2}:$ & $\begin{array}{l}\text { The spread angles corresponding to the } \\
\text { meshing points }\end{array}$ \\
\hline$\theta_{21}$ & $\begin{array}{l}\text { The spread angles corresponding to the } \\
\text { meshing points }\end{array}$ \\
\hline$\theta_{22}$ & $\begin{array}{l}\text { The spread angles corresponding to the } \\
\text { meshing points }\end{array}$ \\
\hline$P:$ & Node \\
\hline$F:$ & Meshing point \\
\hline$f:$ & The length of $P, F$ \\
\hline$S_{u 1 v 1}:$ & The unloading area \\
\hline$S_{u 2 v 2}:$ & The unloading area \\
\hline$f(\varphi)$ & $\begin{array}{l}\text { The relationship between } f \text { and the gear } \\
\text { rotation angle } \varphi\end{array}$ \\
\hline$P_{1}:$ & The pressures of $V_{1}$ \\
\hline$P_{2}:$ & The pressures of $V_{2}$ \\
\hline$P_{\text {in }}:$ & The pressures of the inlet chamber \\
\hline$P_{\text {out }}:$ & The pressures of the outlet chamber \\
\hline$q_{1}:$ & $\begin{array}{l}\text { The unloading flow rate from the trapped oil } \\
\text { cavity } V_{1} \text { to the oil outlet cavity }\end{array}$ \\
\hline$q_{2}:$ & $\begin{array}{l}\text { The unloading flow rate from the trapped oil } \\
\text { cavity } V_{2} \text { to the oil inlet cavity }\end{array}$ \\
\hline$q_{h}:$ & $\begin{array}{l}\text { The unloading flow rate from the trapped oil } \\
\text { cavity } V_{2} \text { to trapped oil cavity } V_{1}\end{array}$ \\
\hline$\rho:$ & The density \\
\hline$\beta:$ & Bulk elastic modulus of the fluid \\
\hline$C:$ & The flow coefficient \\
\hline$V_{h}:$ & Tooth side clearance volume \\
\hline$c_{n 1}:$ & Radial clearance coefficient \\
\hline$c_{n 2}:$ & Radial clearance coefficient. \\
\hline
\end{tabular}

\section{Data Availability}

The data used to support the findings of this study are available from the corresponding author upon request.

\section{Conflicts of Interest}

The authors declare that there are no conflicts of interest regarding the publication of this paper.

\section{Acknowledgments}

This work was supported by Fujian Jiangxia College Cultivation Project (JXZ2019015), the Natural Science Foundation of Fujian Province (2020J01932), and Program for
New Century Excellent Talents in Fujian Province University (Minjiaoke[2018] no. 47).

\section{References}

[1] X. Hao, X. Zhou, X. Liu, and X. Sang, "Pressure ripple of gear pumps affected by air content on trapped volume," Journal of Vibroengineering, vol. 18, no. 6, pp. 4033-4041, 2016.

[2] P. Antoniak, J. Stryczek, M. Banaś et al., "Visualization research on the influence of an ultrasonic degassing system on the operation of a hydraulic gear pump," MATEC Web of Conferences, vol. 211, p. 03005, 2018.

[3] H. Tian, "Dynamic pressure simulation of an external gear pump with relief chamber using a morphological approach," IEEE Access, vol. 6, pp. 77509-77518, 2018.

[4] P. Antoniak and J. Stryczek, "Visualization study of the flow processes and phenomena in the external gear pump," Archives of Civil and Mechanical Engineering, vol. 18, no. 4, pp. 1103-1115, 2018.

[5] F. Sun, Y. Li, C. Wen, and F. Zhong, "Demarcated standard and verification of backlash relief in external gear pumps," Nongye Gongcheng Xuebao/Transactions of the Chinese Society of Agricultural Engineering, vol. 33, no. 20, pp. 61-66, 2017.

[6] M. Hao, Y. Zhou, and S. Hao, "Manufacturing and study on influence of changes in center distance in circle arc-involutecircle arc gear pump operating at high pressure and high speed," Proceedings of the Institution of Mechanical Engineers, Part C: Journal of Mechanical Engineering Science, vol. 230, no. 18, pp. 3285-3297, 2016.

[7] H. Zhou, R. Du, A. Xie, and H. Yang, "Investigations of the micro surface shape for the gear-shaft/journal-bearing interface in water hydraulic internal gear pumps," Advances in Mechanical Engineering, vol. 9, no. 11, pp. 1-15, 2017.

[8] Y. Sun, Y. Yu, and Z. Qi, "Optimization of PGH type gear pump vibration and noise reduction," Journal of Liaoning Technical University (Natural Science Edition), vol. 37, no. 4, pp. 746-749, 2018.

[9] M. Rundo, "Models for flow rate simulation in gear pumps: a review," Energies, vol. 10, no. 9, p. 1261, 2017.

[10] G. Li, L. Zhang, and W. Han, "Profile design and displacement analysis of the low pulsating gear pump," Advances in Mechanical Engineering, vol. 10, no. 3, pp. 179-189, 2018.

[11] J. Zhang and S. Li, "3D flow field analysis of multi-gear pump," Liaoning Gongcheng Jishu Daxue Xuebao (Ziran Kexue Ban)/Journal of Liaoning Technical University (Natural Science Edition), vol. 35, no. 7, pp. 765-769, 2016.

[12] V. N. Syzrantsev and A. A. Pazyak, "Precessional gears for drives of stop valves of oil and gas pipelines and gearboxes of pumps to produce heavy crude oil," Bulletin of the TOMSK Polytechnic University-Geo Assets Engineering, vol. 328, no. 2, pp. 15-27, 2017.

[13] M. Rundo, "Theoretical flow rate in crescent pumps," Simulation Modelling Practice and Theory, vol. 71, pp. 1-14, 2017.

[14] Z. Chen, R. Xu, L. He, and J. Liao, "Modeling an internal gear pump," in Proceedings of the AIP Conference, 1967, no. 1, Article ID 040049, Busan, South Korea, 1967.

[15] K. Park, M. Chang, and D. Jeon, "Precise flowrate control of fluid gear pumps in automated painting systems using a repetitive controller," Applied Sciences, vol. 9, no. 16, p. 3413, 2019.

[16] J. Mo, X. Pan, C. Gu, S. Zheng, and G. Ying, "A thermohydrodynamic analysis of the self-lubricating bearings applied in gear pumps using computational fluid dynamics method," Journal of Tribology, vol. 140, no. 1, 9 pages, 2018. 
[17] G. Li, L. Zhang, W. Han, X. Deng, and Y. Feng, "Pulsation characteristic analysis and tooth profile design of doublecircular-arc helical gear pumps," China Mechanical Engineering, vol. 29, no. 2, pp. 186-192, 2018.

[18] Y. Li, "Impact analysis of composite stiffness in gear pair of external gear pump," Transactions of the Chinese Society of Agricultural Engineering, vol. 27, no. 4, pp. 153-157, 2011.

[19] Y. Li, K. Liu, and F. Sun, "Dynamic model of gears with trapped oil and coupled analysis in external spur-gear pump," Mechanical And Electronics Engineering III, vol. 130-134, pp. 610-615, 2011.

[20] S. Guo and D. Chen, "Calculation of unloading area of internal gear pump and optimization," Mathematical Problems in Engineering, vol. 2020, Article ID 7319871, 9 pages, 2020.

[21] X. Zhao and A. Vacca, "Numerical analysis of theoretical flow in external gear machines," Mechanism and Machine Theory, vol. 108, pp. 41-56, 2017.

[22] Y. Li and F. Sun, "Simulation and theoretical analysis on trapped oil pressure in external gear pump influenced by vibration," Transactions of the Chinese Society of Agricultural Engineering, vol. 28, no. 13, pp. 77-81, 2012.

[23] E. Frosina, A. Senatore, and M. Rigosi, "Study of a highpressure external gear pump with a computational fluid dynamic modeling approach," Energies, vol. 10, no. 6, p. 1113, 2017.

[24] X. Wu, C. Liu, W. Gan, X. Wang, S. Hu, and J. Ji, "Robust design of external gear pump with trapped oil problem," Hangkong Dongli Xuebao/Journal of Aerospace Power, vol. 30, no. 11, pp. 2721-2729, 2015. 